\title{
Cdc42 and Rac1 Signaling Are Both Required for and Act Synergistically in the Correct Formation of Myelin Sheaths in the CNS
}

\author{
Tina Thurnherr, ${ }^{1 *}$ Yves Benninger, ${ }^{1 *}$ Xunwei Wu, ${ }^{2}$ Anna Chrostek, ${ }^{3}$ Sven M. Krause, ${ }^{1}$ Klaus-Armin Nave, ${ }^{4}$ \\ Robin J. M. Franklin, ${ }^{5}$ Cord Brakebusch, ${ }^{2}$ Ueli Suter, ${ }^{1}$ and João B. Relvas ${ }^{1}$ \\ ${ }^{1}$ Institute for Cell Biology, Department of Biology, Federal Institute of Technology (ETH) Zurich, CH-8093 Zurich, Switzerland, ${ }^{2}$ Department of Molecular \\ Pathology, University of Copenhagen, 2100 Copenhagen, Denmark, ${ }^{3}$ Department of Molecular Medicine, Max Planck Institute for Biochemistry, \\ D-82152 Martinsried, Germany, ${ }^{4}$ Department of Neurogenetics, Max Planck Institute of Experimental Medicine, 37075 Goettingen, Germany, and \\ ${ }^{5}$ Cambridge Centre for Brain Repair and Neuroregeneration Laboratory, Department of Veterinary Medicine, University of Cambridge, Cambridge \\ CB3 0ES, United Kingdom
}

The formation of myelin sheaths in the CNS is the result of a complex series of events involving oligodendrocyte progenitor cell (OPC) proliferation, directed migration, and the morphological changes associated with axon ensheathment and myelination. To examine the role of Rho GTPases in oligodendrocyte biology, we have used a conditional tissue-specific gene-targeting approach. Ablation of $C d c 42$ in cells of the oligodendrocyte lineage did not affect OPC proliferation, directed migration, or in vitro differentiation, but it led to the formation of a unique and stage-specific myelination phenotype. This was characterized by the extraordinary enlargement of the inner tongue of the oligodendrocyte process and concomitant formation of a myelin outfolding as a result of abnormal accumulation of cytoplasm in this region. Ablation of Racl also resulted in the abnormal accumulation of cytoplasm in the inner tongue of the oligodendrocyte process, and we provide genetic evidence that rac1 synergizes with cdc 42 in a gene dosage-dependent way to regulate myelination.

Key words: cdc42; rac1; Rho GTPase; myelin; CNS; oligodendrocyte

\section{Introduction}

During oligodendrocyte development, the coordinated interpretation of extracellular cues, such as integrin, growth factor, or chemokine receptor activation, allows oligodendrocytes to sense their environment and regulate their intrinsic developmental program (Miller, 2002; Baron et al., 2005). This process is likely to involve the GTPases of the Rho subfamily of which cdc42, rac1, and rhoA are the most well studied members. These molecules, best known for their roles in regulating signaling pathways linking extracellular stimuli to the assembly and organization of the actin cytoskeleton (Hall, 1998), also control microtubule dynamics, cell polarity, membrane trafficking, and gene transcription (Etienne-Manneville and Hall, 2002; Jaffe and Hall, 2005). In the context of CNS myelination, pathways known to influence oligodendrocyte development such as those initiated by the activation of integrin receptors (Liang et al., 2004) or the transmembrane protein Lingo-1 (Mi et al., 2005) can modulate the activities of cdc42, rac1, and rhoA. These GTPases are expressed by oligoden-

\footnotetext{
Received May 22, 2006; revised Aug. 16, 2006; accepted Aug. 20, 2006.

This work was supported by a Technische Hochschule grant from the Federal Institute of Technology (ETH) Zurich (T.T., Y.B., U.S., J.B.R.) and by the Swiss National Science Foundation and the National Center for Competence in Research "Neural Plasticity and Repair" (U.S.). We thank Mike Peacock for his assistance, and Ned Mantei, Suzana Atanasoski, and Lukas Sommer for critically reading this manuscript.

*T.T. and Y.B. contributed equally to this work.

Correspondence should be addressed to João B. Relvas, Institute for Cell Biology, Department of Biology, Federal Institute of Technology (ETH) Zurich, CH-8093 Zurich, Switzerland. E-mail: joao.relvas@cell.biol.ethz.ch. DOI:10.1523/JNEUROSCI.2158-06.2006

Copyright $\odot 2006$ Society for Neuroscience $\quad 0270-6474 / 06 / 2610110-10 \$ 15.00 / 0$
}

drocytes (Erschbamer et al., 2005), and, in primary oligodendrocyte cultures, their expression and activity are developmentally regulated (Liang et al., 2004). Although rhoA is expressed and active during early progenitor stages, the expression and activity of cdc42 and racl increase as differentiation proceeds (Liang et al., 2004). Perturbation of the activities of these GTPases by expression of corresponding dominant-negative or constitutively active mutant molecules led to the conclusion that cdc 42 and $\mathrm{rac} 1$ act as positive regulators of morphological differentiation, inducing process extension and branching, whereas rhoA acts as a negative regulator, inhibiting process extension (Liang et al., 2004). Cdc42 itself is thought to play a key role in establishing eukaryotic cell polarity, a fundamental requirement for cell proliferation, migration, and morphogenesis (Etienne-Manneville, 2004). This makes cdc42 an attractive candidate molecule to regulate several other aspects of oligodendrocyte biology, including those associated with the ensheathment and myelination of axons.

In this study, we examine the role of cdc42 and rac1 signaling during myelination of the developing CNS by using tissuespecific conditional gene ablation in the oligodendrocyte lineage. This approach circumvents potential problems associated with the use of dominant-negative Rho GTPase mutants (Braga et al., 2000; Czuchra et al., 2005) and examines rigorously the requirements for these GTPases under physiological conditions. Our data indicate a stage-specific and critical role for cdc42 and rac1 in myelination. Furthermore, cdc42 synergizes with racl in the regulation of this crucial process. 


\section{Materials and Methods}

Antibodies. The following primary antibodies were used for this study: monoclonal antibodies against myelin-associated glycoprotein (MAG) (Chemicon, Temecula, CA; 1:1000), myelin basic protein (MBP) (Serotec, Oxford, UK; 1:75), 2',3'-cyclic nucleotide 3'-phosphodiesterase (CNPase) (Santa Cruz Biotechnology, Santa Cruz, CA; 1:500), myelin oligodendrocyte glycoprotein (MOG) (R \& D Systems, Minneapolis, MN; 1:1000), $\beta$-actin (Sigma, St. Louis, MO; 1:1000), and rac1 (BD Biosciences, Franklin Lake, NJ; 1:1000); polyclonal antibodies against proteolipid protein (PLP) (A341; 1:500; from K. A. Nave, Max Planck Institute of Experimental Medicine, Göttingen, Germany) and cdc42 (Santa Cruz Biotechnology; 1:1000). Secondary antibodies for Western blots were obtained from Pierce (Rockford, IL) and Santa Cruz Biotechnology; for immunocytochemistry, they were obtained from Jackson ImmunoResearch (West Grove, PA).

Generation of conditional knock-out mice. The generation of conditional Cdc42 mutant mice (Wu et al., 2006) and Rac1 mutant mice (Chrostek et al., 2006) have been described previously. Mice homozygous for the $C d c 42$ floxed allele $\left(C d c 42^{\text {lox/lox }}\right)$ were crossed with mice heterozygous for the $C d c 42$ floxed allele, which expressed the Cre recombinase under the control of the CNPase $\left(\mathrm{Cnp}-\mathrm{Cre}{ }^{+} \mathrm{Cdc} 42^{\text {lox/wt }}\right)$ (Genoud et al., 2002; Lappe-Siefke et al., 2003; Saher et al., 2005), to obtain single $C d c 42$ homozygous mutants $\left(\mathrm{Cnp}-\mathrm{Cr} e^{+} \mathrm{Cdc} 42^{\text {lox/lox }}\right)$ and single $C d c 42$ heterozygous mutant $\left(\mathrm{Cnp}-\mathrm{Cr} e^{+} \mathrm{Cdc42} 2^{\text {lox/wt }}\right)$ mice. To generate double transgenic mice with different allelic combinations, double heterozygous mutants $\left(\mathrm{Cnp}-\mathrm{Cr} e^{+} \mathrm{Cdc} 42^{\text {lox/wt }} \mathrm{Racl}^{\text {lox/wt) }}\right.$ were crossed with mice homozygous for both the $C d c 42$ and the Rac1 floxed alleles

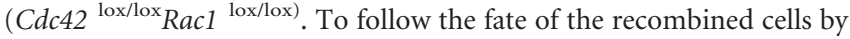
detection of $\beta$-galactosidase expression, we bred the conditional LacZ allele from the ROSA26 reporter mouse strain (Soriano, 1999) into control and mutant mice. Cnp-Cre is active in $>70 \%$ of all oligodendroglial cells (Benninger et al., 2006). Genotypes were determined by performing PCR on genomic DNA. The breeding strategy to produce mutant and control Rac1 mice was the same as described for $C d c 42$ mice.

Semithin and electron microscopy analysis. Mice were deeply anesthetized and then perfused with $0.1 \mathrm{M}$ phosphate buffer, $\mathrm{pH} 7.4$, followed by buffer containing $3 \%$ glutaraldehyde and $4 \%$ paraformaldehyde (PFA). Fixed tissues were postfixed in $2 \%$ osmium tetroxide, dehydrated through a graded acetone series, and embedded in Spurrs resin (Electron Microscopy Sciences, Hatfield, PA). Semithin sections were stained with toluidine blue for analysis at the light microscope, and ultrathin sections were stained with $3 \%$ uranyl acetate and $1 \%$ lead citrate before observation in a Hitachi H-600 TEM at $75 \mathrm{kV}$. For growth ratio and axon diameter calculations, at least 150 myelinated axons from the anterolateral fiber tracts of postnatal day 24 (P24) control and mutant spinal cords were measured with MCID software (Imaging Research, St. Catharines, Ontario, Canada). Mutant fiber profiles with myelin sheath outfoldings on the plane of analysis were not included in the analysis.

The frequency of myelin sheath outfoldings was calculated at a magnification of $630 \times$ on semithin cross sections obtained from lower thoracic regions of the spinal cord of single and double transgenics. All myelin sheaths protruding away from the axolema of axons localized in the anterolateral fiber tracts were included in the analysis. The final number of myelin outfoldings calculated for each control or mutant spinal cord was the average of the outfoldings present in at least three different cross sections.

Immunofluorescence and terminal deoxynucleotidyl transferase-mediated biotinylated UTP nick end labeling staining. Frozen tissue sections and oligodendrocyte cultures were fixed in 4\% PFA/PBS, incubated overnight with primary antibodies in $0.1 \%$ Triton X-100/PBS, washed in PBS, and incubated with the appropriate secondary antibodies. Apoptotic cell death was analyzed by terminal deoxynucleotidyl transferase-mediated biotinylated UTP nick end labeling (TUNEL) staining with biotinlabeled UTP- and fluorescein isothiocyanate-conjugated streptavidin complex according to the manufacturer's instructions (Roche Diagnostics, Pleasantson, CA). Images were acquired with a Zeiss fluorescence microscope equipped with a Zeiss Axiocam CCD camera, and Axio Vi-
sionV4.5 (Zeiss, Oberkochen, Germany) acquisition software. Pictures were prepared with Adobe Photoshop version 8.0.

In situ hybridization. Frozen tissue sections $(20 \mu \mathrm{m})$ were collected and hybridized with digoxigenin-labeled RNA probes overnight at $72^{\circ} \mathrm{C}$ in buffer containing 50\% formamide. The bound probe was detected with an anti-digoxigenin antibody, conjugated with alkaline phosphatase (Roche Diagnostics). The MBP plasmid was a kind gift of Dr. W. D. Richardson (University College London, UK).

Primary cell culture. Oligodendrocyte progenitor cells (OPCs) were purified from mixed glial cultures (McCarthy and de Vellis, 1980) and differentiated on extracellular matrix substrates (Relvas et al., 2001). For 5 -bromo-4-chloro-3-indolyl- $\beta$-D-galactopyranoside (X-gal) staining, cells were fixed in $2 \%$ formaldehyde and $0.2 \%$ glutaraldehyde in PBS for $7 \mathrm{~min}$ and stained in X-gal staining solution $\left[5 \mathrm{mM} \mathrm{K}_{3}\left[\mathrm{Fe}(\mathrm{CN})_{6}\right], 5 \mathrm{~mm}\right.$ $\mathrm{K}_{4}\left[\mathrm{Fe}(\mathrm{CN})_{6}\right], 2 \mathrm{~mm} \mathrm{MgCl}_{2}$, and $1 \mathrm{mg} / \mathrm{ml}$ of X-gal (Calbiochem, La Jolla, $\mathrm{CA}$ ) in PBS] overnight at $37^{\circ} \mathrm{C}$ as described previously (Benninger et al., 2006). Proliferation was measured with the 5-Bromo- 2 '-Deoxyuridine Labeling and Detection Kit I (Roche Diagnostics) according to the manufacturer's instructions. Apoptotic cell death was analyzed by TUNEL according to the manufacturer's instructions (Roche Diagnostics).

Western blot. Purified oligodendrocytes and spinal cord tissue were homogenized in lysis buffer [0.1\% SDS, $10 \mathrm{~mm}$ Tris- $\mathrm{HCl}, 150 \mathrm{~mm} \mathrm{NaCl}$, $50 \mathrm{~mm} \mathrm{NaF}, 1 \mathrm{~mm} \mathrm{NaVO}_{4}, 1 \mathrm{~mm}$ EDTA, 0.5\% sodium-deoxycholate, protease inhibitor mixture (Sigma)]. Proteins were separated with standard SDS-PAGE and electroblotted onto polyvinylidene difluoride membranes (Hybond-C, Amersham Biosciences, Arlington Heights, IL) by using standard protocols. Densitometry of the relative levels of protein expression was performed with Quantity One software (Bio-Rad, Hercules, CA).

Rho GTPase activity. The glutathione S-transferase-p21-activated kinase-Cdc42/Rac interactive binding motif domain (GST-PAK-CD) construct was a kind gift of Dr. J. Collard (The Netherlands Cancer Institute, Amsterdam, The Netherlands). Racl activity was measured as described previously (Sander et al., 1998). After lysis, supernatants were incubated with GST-PAK-CD fusion protein bound to glutathione-coupled Sepharose beads (Amersham Biosciences) at $4^{\circ} \mathrm{C}$ for $30 \mathrm{~min}$. The beads were then washed, and the protein was eluted in Laemmli sample buffer and analyzed by Western blotting.

Cell migration. Directed OPC migration was assayed with a 24-well Boyden chamber according to the instructions of the manufacturer (BD Biosciences). Filters were coated with $5 \mu \mathrm{g} / \mathrm{ml}$ of poly-D-lysine (PDL), and $5 \times 10^{4}$ OPCs were loaded into each well. To induce migration, different concentrations of platelet-derived growth factor (PDGF) or netrin-1 (Prepotec, Rocky Hill, NJ) were added to either the upper or lower chambers. Cells were allowed to migrate for $10-12 \mathrm{~h}$ at $37^{\circ} \mathrm{C}$ and fixed, and the number of $4^{\prime}, 6^{\prime}$-diamidino-2-phenylindole-positive migrated cells was quantified on the lower surface of the filter.

\section{Results}

\section{Recombination of the conditional $C d c 42$ allele in the CNS of mutant mice}

To study the role of cdc42 signaling in oligodendrocytes, we conditionally ablated $C d c 42$ by expressing Cre-recombinase (Cre) under the control of CNPase gene regulatory sequences (LappeSiefke et al., 2003; Saher et al., 2005; Benninger et al., 2006) (Fig. $1 A$ ). In the CNS, Cre is active in premyelinating oligodendrocytes and in some spinal motoneurons from embryonic day (E) 12 (Genoud et al., 2002). To identify the recombined cells, we bred the conditional LacZ allele from the ROSA26 reporter mouse (Soriano, 1999) into control and mutant mice. Recombination of the conditional $C d c 42$ allele (Fig. $1 B$ ) led to the loss of cdc42 mRNA signal in the white matter and in spinal motoneurons of the mutant spinal cord (Fig. $1 C$ ) and to a strong reduction $(66.5 \pm 14 \% ; p=0.00008 ; n=4)$ in $c d c 42$ protein in mutant OPC cultures. The low cdc42 level of expression detected in the mutant lysates was probably caused by the presence of a small percentage of contaminating astrocytes and unrecombined, 
cdc42-positive OPCs in the mutant cultures. In these cultures, $76 \%$ of mutant OPCs were recombined as assessed by $\mathrm{X}$-gal staining.

CNP-Cre is also active in the Schwann cells of the peripheral nervous system (PNS), and, as a result, mutant $C d c 42$ mice displayed a progressive hindlimb paresis consistent with a severe PNS dysmyelinating phenotype (Y. Benninger, unpublished observations).

\section{Cdc42 is required for proper}

ensheathment and myelination of axons Examination of cross sections of spinal cord fiber tracts, optic nerve, and midsagittal corpus callosum of P24 Cdc42 mutant mice revealed the presence of abnormal myelin outfoldings, here defined as areas of the internode where the myelin sheath protrudes away from the axon surface (Fig. 2Ad,Af,Ah). These abnormal structures were already identifiable in the mutant spinal cord at P5 (Fig. 2Ab). At P24, with the addition of further myelin wraps, the outfoldings grew larger (Fig. 2Ad). During early stages of myelination, excess cytoplasm was found in the innermost uncompacted lamellae and the inner tongue of a large number of profiles (Fig. $2 A, B$ ). In profiles with larger outfoldings, the innermost lamellae became gradually compacted, whereas the inner tongue grew in size, possibly as a consequence of the extrusion of the cytoplasm from the innermost lamellae into the inner tongue (Fig. $2 B$ ).

Examination of longitudinal sections of the spinal cord showed that at early stages of myelination the excess cytoplasm occupied relatively large areas of the internodes (Fig. $3 A$ ). With ongoing myelination, the excessive cytoplasm became confined to the concomitantly growing myelin sheath outfolding (Figs. 2B, 3).

These abnormalities were randomly distributed along the internode, and no obvious differences were observed in the spacing, size, or cytoarchitecture of the node and paranode regions. At P24, measurements performed in transverse profiles, excluding myelin outfoldings, showed that the myelin sheaths in the mutant spinal cord (Fig. $2 \mathrm{Ad}$ ) were significantly thinner (Fig. 4A) than those in control spinal cords (Fig. $2 A c$ ). It is likely that the formation of the outfoldings expended myelin that would otherwise have been used to form additional myelin wrappings, thereby causing a reduction in myelin thickness. The loss of cdc42 did not alter the relative amounts of MAG, PLP, CNPase, MBP, and MOG in the spinal cords of mutant mice (Fig. $4 B$ ). The periodicity in mutant myelin was normal, with a major dense line spacing of $15 \mathrm{~nm}$ (Fig. 4C).

To eliminate the possibility that axon shrinkage contributed to the formation of myelin outfoldings, we measured axon diameters in P24 control and mutant spinal cords and assigned them to four pre-established size categories ( $<1 \mu \mathrm{m}, 1-2 \mu \mathrm{m}, 2-3 \mu \mathrm{m}$, and $>3 \mu \mathrm{m})$. No significant differences were observed in the percentages of control and mutant axons whose axon diameters were $<1 \mu \mathrm{m}(21.3 \pm 8.08$ and $18.3 \pm 4.61 \% ; p=0.61), 1-2 \mu \mathrm{m}$ (48.3 \pm 6.11 and $40.6 \pm 5.50 \% ; p=0.18), 2-3 \mu \mathrm{m}(20.6 \pm 2.886$ and $25.3 \pm 2.51 \% ; p=0.10)$, or $3-4 \mu \mathrm{m}(8.3 \pm 5.85$ and $12.3 \pm$ $4.93 \% ; p=0.41$ ) (Fig. $4 D$ ). Our results indicate that axon shrinkage was not an important feature of mutant spinal cords and thus did not play a role in the formation of the myelin outfoldings.

\section{Cdc42 is not required for OPC morphological differentiation in vitro}

To investigate whether the myelin abnormalities observed in the Cdc42 mutant CNS could be directly attributed to impairment of oligodendrocyte process extension and branching (Liang et al., 2004), control and mutant OPCs were allowed to differentiate in culture (Buttery and ffrench-Constant, 1999; Relvas et al., 2001). OPC differentiation in culture involves process extension and formation of myelin membranes. After $3 \mathrm{~d}$ of differentiation on PDL substrates, cells were fixed and stained for X-gal, and randomly chosen mutant and control recombined (X-gal positive) oligodendrocytes were scored and assigned to five preestablished categories according to their morphological com- 
A

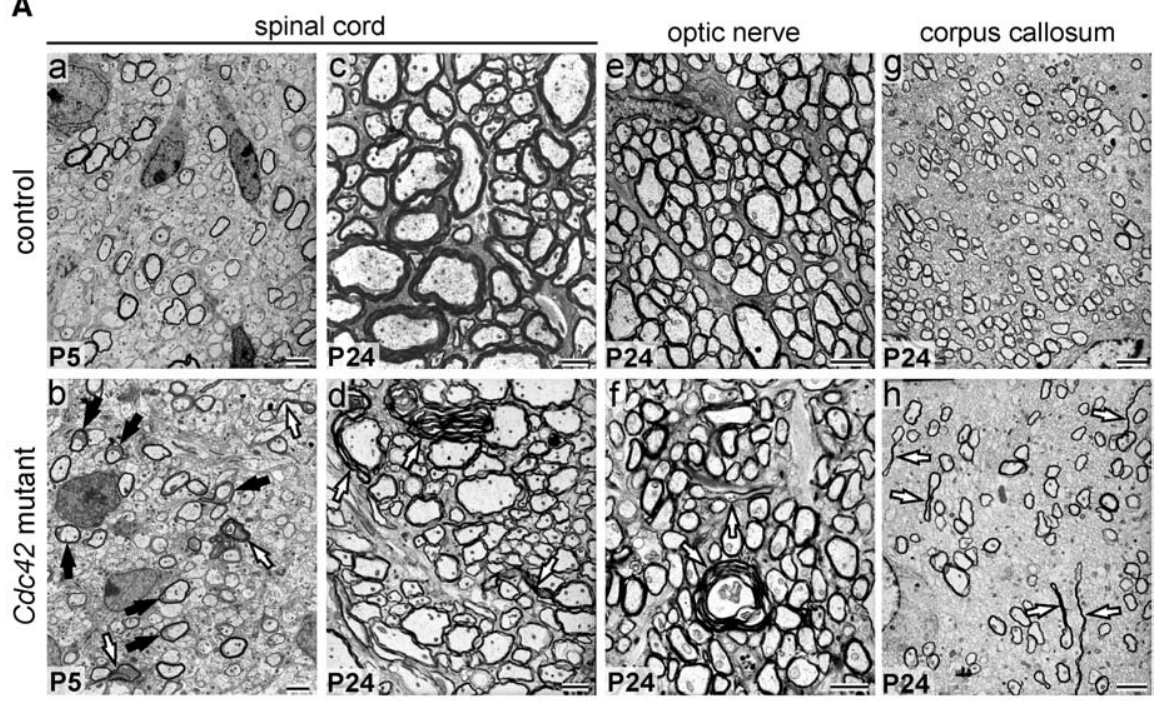

B
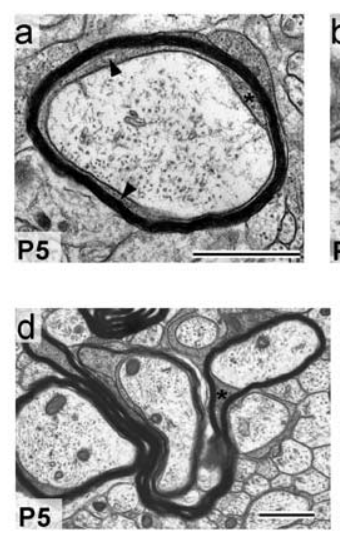

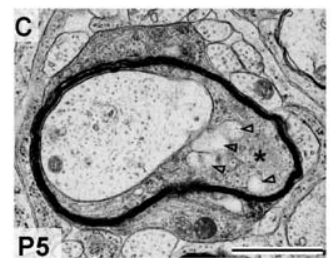

P5

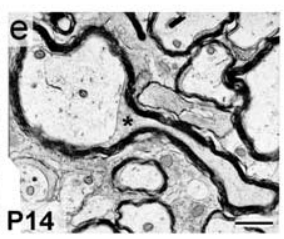

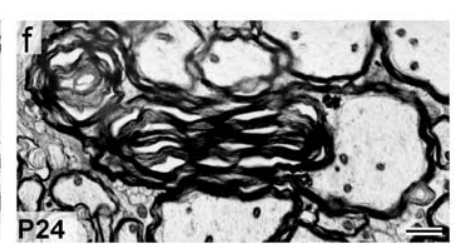

Figure 2. Cross sections of spinal cord, optic nerve, and midsagittal corpus callosum of control and (dc 42 mutant mice. A, At P5, fiber profiles with excess cytoplasm (black arrows) and myelin sheath outfoldings (white arrows) are present in mutant $(\boldsymbol{A} \boldsymbol{b})$ but not in control (Aa) spinal cord. At P24, the mutant spinal cord (Ad), optic nerve (Af), and corpus callosum ( $\boldsymbol{A} \boldsymbol{h})$ contain profiles with large myelin sheath outfoldings. Such defects are found only very rarely in P24 control spinal cord $(\boldsymbol{A c})$, optic nerve $(\boldsymbol{A e})$, or corpus callosum (Ag). Scale bars, $2 \mu \mathrm{m}$. $\boldsymbol{B}$, Excess cytoplasm in the innermost loops and inner tongue of mutant profiles in the spinal cord. $\boldsymbol{B} \boldsymbol{a}$, In P5 control profiles, the compacted myelin sheath is apposed to the axolemma, and only moderate amounts of cytoplasm are in the inner loop (black arrowheads) and inner tongue (asterisk). $\boldsymbol{B} \boldsymbol{b}$, In many mutant profiles, excess cytoplasm is present in the innermost loops (pound signs) and inner tongue. $\boldsymbol{B} \boldsymbol{c}$, The inner tongue occasionally contains large vesicles (open arrowheads). At P5 (Bd), P14 (Be), and especially at P24 (Bf), the myelin outfoldings can be large and complex. Scale bars, $1 \mu \mathrm{m}$.

plexity (Liang et al., 2004). Category 1 was used to describe cells with the lowest degree of morphological complexity, and category 5 was used to describe cells with the highest. In each of the three independent experiments, $>250$ mutant and control recombined oligodendrocytes were examined and assigned to the different categories. No significant differences were observed in the percentage of control and mutant cells displaying category 1 morphology (30.4 \pm 2.68 and $28.6 \pm 3.88 \% ; p=0.53)$, category 2 morphology ( $32 \pm 3$ and $35.7 \pm 4.51 \% ; p=0.31$ ), category 3 morphology $(21.7 \pm 1.53$ and $19.8 \pm 4.61 \% ; p=0.54)$, category 4 morphology (14.1 \pm 2.85 and $13.9 \pm 2.15 \% ; p=0.93)$, or category 5 morphology $(1.8 \pm 2.04 \%$ and $2.1 \pm 1.15 \% ; p=0.82)$ (Fig. $5 A, B$ ). In addition, no significant differences were found in the percentage of MBP-positive cells present in control and mutant cultures plated on PDL (36 \pm 9.47 and $36 \pm 8.13 \%$; $p=$ $0.97)$, fibronectin (FN) $(32 \pm 4.11$ and $32 \pm 4.03 ; p=0.88)$ or laminin-2 (LM) $(32 \pm 5.25$ and $35 \pm 6 \%$; $p=0.65)$. Furthermore, the area of myelin membrane formed by control and mutant MBP-positive cells was not significantly different on PDL $(5123 \pm 368$ and $4939 \pm$ $\left.608 \mu \mathrm{m}^{2} ; p=0.61\right), \mathrm{FN}(5192 \pm 695$ and $\left.5205 \pm 948 \mu \mathrm{m}^{2} ; p=0.98\right)$, or $\mathrm{LM}$ $\left(5467 \pm 780\right.$ and $4828 \pm 900 \mu \mathrm{m}^{2} ; p=$ 0.27 ) substrates (Fig. $5 C$ ). We conclude that $\mathrm{cdc} 42$ is not required for OPC differentiation in culture.

\section{Oligodendrocytes lacking cdc42 disperse and colonize the spinal cord normally}

Rho GTPase family members, and cdc42 in particular, are thought to be widely involved in the directed migration of cells in response to tropic cues (Ridley et al., 2003). If cdc 42 were involved in the migration of OPCs away from their germinal zones, one would predict a reduced dispersion of OPCs and oligodendrocytes throughout the developing CNS, including the spinal cord; however, the distribution of oligodendrocytes positive for MBP mRNA in the ventral and dorsal fiber tracts of control and mutant mouse thoracic spinal cord was not significantly different at $\mathrm{P} 1(8.9 \pm 1.2$ and $9.4 \pm 0.6 \% ; p=$ $0.76)$ or P5 (18.9 \pm 2 and $18.4 \pm 1.17 \%$; $p=0.82$ ) (Fig. 6A), suggesting that $\operatorname{cdc} 42$ is largely dispensable for OPC dispersion.

This conclusion was also supported by standard in vitro migration assays (Boyden chamber; see Material and Methods) with which we tested the capacity of freshly isolated control and mutant OPC to migrate in response to PDGF, an OPC chemoattractant secreted along OPC migratory pathways (McKinnon et al., 1993), or netrin-1, an OPC chemorepellent expressed at the ventricular zone during OPC emigration (Jarjour et al., 2003).

OPCs migrate toward sources of PDGF. Accordingly, the addition of 10 $\mathrm{ng} / \mathrm{ml}$ of PDGF to the lower chamber of the wells significantly increased control OPC migration $(p=$ 0.03 ) in relation to wells to which no PDGF was added. In the absence of cdc42, mutant OPCs migrated as well as controls in wells without PDGF $(0.97 \pm 0.06$ and $1 \pm 0 ; p=0.47)$ or in wells to which $1 \mathrm{ng} / \mathrm{ml}(1.13 \pm 0.09$ and $1 \pm 0.26 ; p=0.23)$ or $10 \mathrm{ng} / \mathrm{ml}$ $(1.49 \pm 0.26$ and $1.51 \pm 0.34 ; p=0.48)$ of PDGF was added to the lower chamber. Mutant and control OPC migration was also not significantly different in wells to which $10 \mathrm{ng} / \mathrm{ml}$ of PDGF was added to the top chamber $(0.79 \pm 0.14$ and $0.77 \pm 0.23 ; p=0.45)$ or simultaneously to both top and bottom chambers $(0.99 \pm 0.05$ and $0.99 \pm 0.03 ; p=0.44$ ) (Fig. $6 B$ ).

Netrin-1 acts as an OPC chemorepellent. Consequently, in wells to which 25 or $100 \mathrm{ng} / \mathrm{ml}$ of netrin-1 was added to the bottom chamber, control OPC migration toward the lower surface of the filter was inhibited significantly $(p=0.01$ and 0.009 , 
respectively), as compared with wells to which no netrin-1 was added; however, control and mutant OPCs migrated equally well in wells without netrin-1 or when $25 \mathrm{ng} / \mathrm{ml}(0.75 \pm 0.06$ and $0.73 \pm$ $0.02 ; p=0.27)$ or $100 \mathrm{ng} / \mathrm{ml}(0.59 \pm 0.19$ and $0.56 \pm 0.05 ; p=0.39)$ of netrin- 1 was added to the lower chamber. Control and mutant OPC migration was also not significantly different $(0.59 \pm 0.19$ and $0.56 \pm 0.05 ; p=0.34$ ) when $100 \mathrm{ng} / \mathrm{ml}$ of netrin-1 was added to the top chamber of the well (Fig. 6B). We conclude that the lack of cdc42 did not impair the migration of mutant OPCs in response to PDGF or netrin-1.

OPCs were also able to proliferate and survive normally in the absence of cdc42 (Fig. 6C,D). As expected, in in vitro proliferation assays, the percentage of control bromodeoxyuridine (BrdU)-positive cells increased with the addition of PDGF (Fig. $6 C)$, which also acts as an OPC mitogen (Besnard et al., 1987). Control OPC proliferation was significantly higher in the presence of $10 \mathrm{ng} / \mathrm{ml}$ of PDGF than in the presence of $5 \mathrm{ng} / \mathrm{ml}$ of PDGF $(p=0.03)$ or $1 \mathrm{ng} / \mathrm{ml}$ of PDGF $(p=0.01)$ or without PDGF $(p=0.002)$. In relation to control cells, the lack of cdc42 did not significantly impair mutant OPC proliferation in the absence of PDGF (27.6 \pm 7.86 and $25 \pm$ $2.28 \% ; p=0.31)$ or in the presence of 1 $\mathrm{ng} / \mathrm{ml}(30.1 \pm 3.07$ and $33.8 \pm 6.19 \% ; p=$ $0.2), 5 \mathrm{ng} / \mathrm{ml}(38.3 \pm 4.29$ and $38.0 \pm$ $3.89 \% ; p=0.46)$, or $10 \mathrm{ng} / \mathrm{ml}(53 \pm 6.87$ and $51.9 \pm 3.19 \% ; p=0.41$ ) of PDGF (Fig. 6C).

PDGF is also a survival factor for OPCs (Barres et al., 1992), and PDGF increased control OPC cell survival in a dosagedependent manner. The percentage of control apoptotic TUNEL-positive cells in the absence of PDGF was significantly higher than in the presence of $0.1 \mathrm{ng} / \mathrm{ml}(p=0.02), 1 \mathrm{ng} / \mathrm{ml}$ ( $p=$ $0.018)$, or $10 \mathrm{ng} / \mathrm{ml}$ ( $p=0.005)$ of PDGF. The percentage of mutant TUNEL-positive OPCs was not significantly different from controls in the absence of PDGF (50.7 \pm 5.35 and $51 \pm$ $1.23 \% ; p=0.83)$ or in the presence of $1 \mathrm{ng} / \mathrm{ml}(42.9 \pm 2.59$ and $43.4 \pm 1.86 \% ; p=0.41)$ or $10 \mathrm{ng} / \mathrm{ml}(21.6 \pm 1.45$ and $25 \pm$ $3.65 \% ; p=0.1)$ of PDGF; it was even lower $(45 \pm 1.06$ and $49.3 \pm$ $1.63 \% ; p=0.02$ ) in the presence of $0.1 \mathrm{ng} / \mathrm{ml}$ of PDGF (Fig. $6 D$ ).

\section{Racl is required for proper axon ensheathment} and myelination

Cdc42 and rac1 cooperate in pathways regulating important cellular functions (Cotteret and Chernoff, 2002). During OPC differentiation, $c d c 42$ and rac 1 show a similar pattern of activity and expression (Liang et al., 2004), raising the possibility that these two molecules act synergistically to regulate different stages of oligodendrocyte development. Therefore, having shown that cdc42 is required for the normal ensheathment and myelination of axons, we questioned whether racl also regulates this process. To determine this, we targeted the recombination and ablation of a Rac1 conditional allele to oligodendrocytes as in $C d c 42$ mutants
B

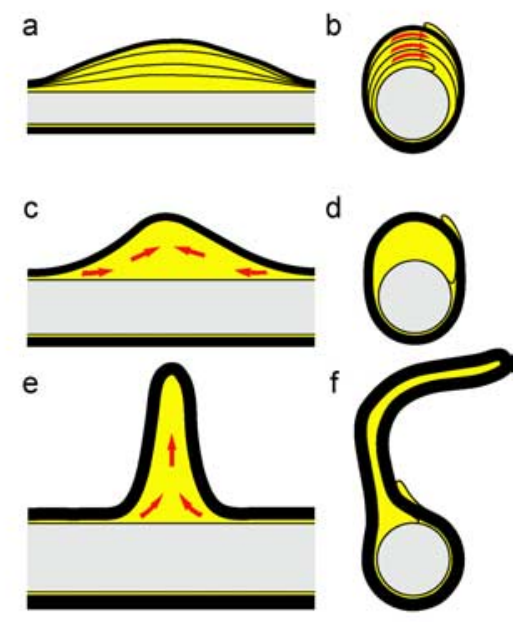

Figure 3. Internodal profiles of myelinated fibers in control and mutant spinal cords. Aa, In the control P5 fiber, the myelin sheath (black arrowheads) is apposed to the axolemma. $\boldsymbol{A} \boldsymbol{b}$, In P5 mutant fibers, excess cytoplasm is found in uncompacted lamella (white arrows) and in the inner tongue (asterisk). On the opposite side of the fibers, the myelin sheath is compacted and 列

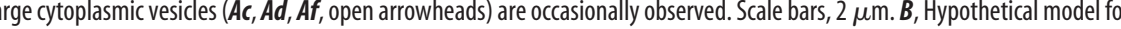
the pathogenesis of myelin sheath outfoldings: mutant internodal profiles $(\mathbf{B a}, \mathbf{B C}, \mathbf{B e})$ and their corresponding cross-sectiona indicate flow of the excess cytoplasm during the formation of the outfoldings.

(see Material and Methods). Examination of P24 spinal cord of Rac1 mutants revealed the presence of myelin outfoldings similar to these observed in the $C d c 42$ mutants (Fig. 7), showing that rac1 is also required for proper myelination.

\section{Cdc42 and racl synergize to regulate pathways controlling CNS myelination}

Although the ablation of either $C d c 42$ or Rac1 led to the formation of myelin outfoldings, this phenotype could still be caused by impairment of different, independent rac1- and cdc42-regulated pathways. To address this point, we generated mice carrying at least one recombined $C d c 42$ and one recombined $R a c 1$ allele (see Material and Methods). We then compared the number of myelin outfoldings present on semithin sections obtained from P24 spinal cords of double and single transgenic mice (Fig. $8 A, B$ ). We hypothesized that if cdc42 and racl synergize in pathways regulating axon ensheathment and myelination, the myelin outfoldings should reflect, to a large extent, the number of recombined alleles present in each transgenic mouse, i.e., should be "genedosage" dependent. The results (Fig. $8 \mathrm{~B}$ ) showed the following: (1) the numbers of outfoldings in wild-type $\left(30 \pm 3 / 0.5 \mathrm{~mm}^{2}\right)$ single heterozygous $C d c 42\left(22 \pm 6 / 0.5 \mathrm{~mm}^{2}\right)$ and single heterozygous Racl $\left(29 \pm 1 / 0.5 \mathrm{~mm}^{2}\right)$ were very low and not significantly different; (2) the numbers of outfoldings in double heterozygous mutant mice were significantly higher $(167 \pm 38 / 0.5$ $\mathrm{mm}^{2} ; p=0.02$ ) than those in single $C d c 42$ or Racl heterozygous mutant mice; (3) the numbers of outfoldings in single $C d c 42$ 
A

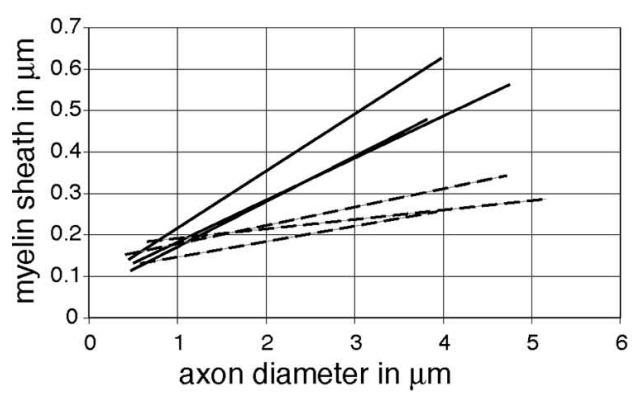

B
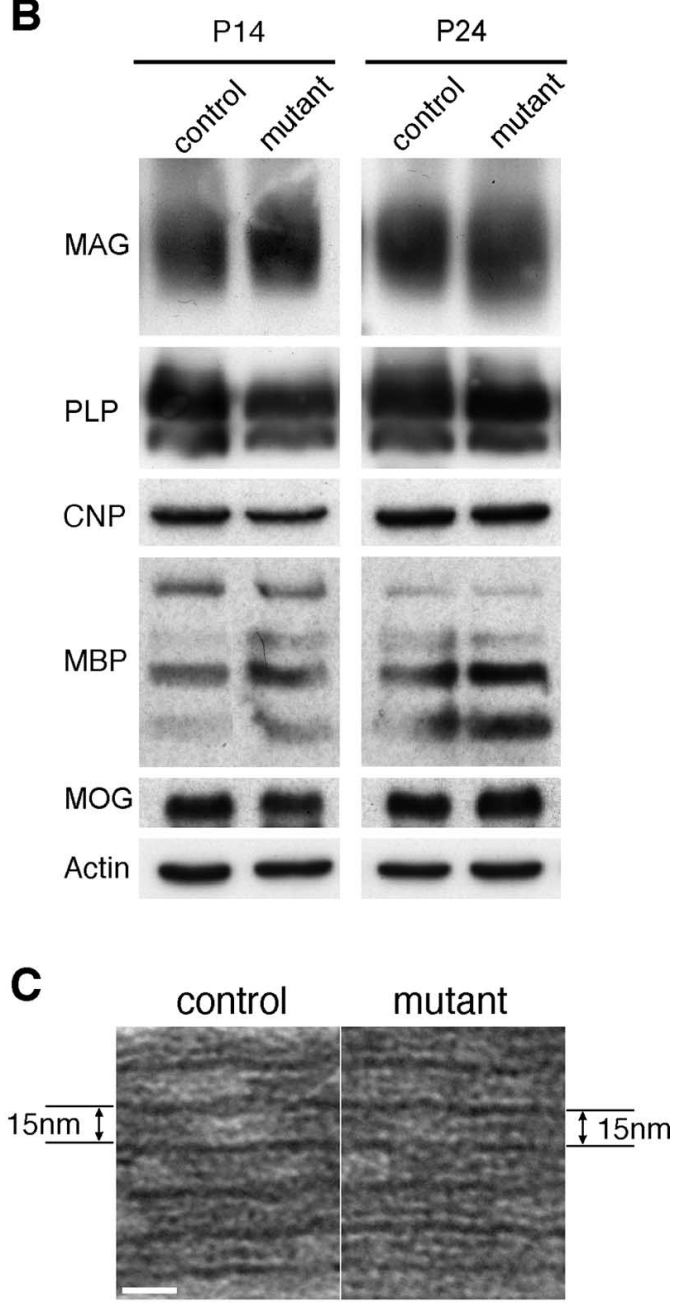

D

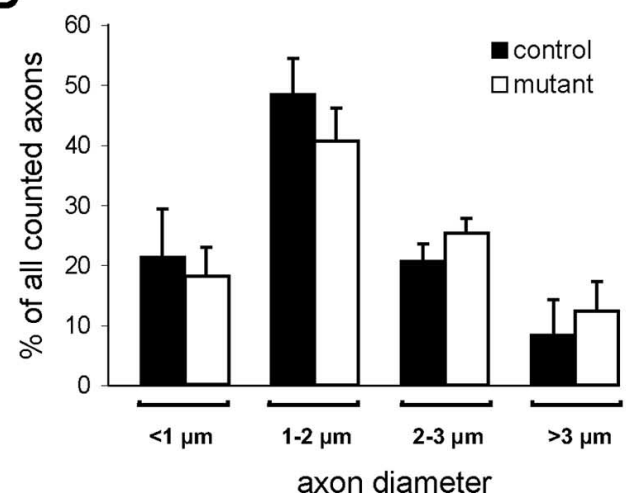

homozygous mutant mice were significantly higher (1094 $\pm 146 /$ $\left.0.5 \mathrm{~mm}^{2} ; p=0.0035\right)$ than those in single Racl homozygous mutant mice ( $\left.579 \pm 48 / 0.5 \mathrm{~mm}^{2}\right)$; (4) the numbers of outfoldings in Rac1 homozygous/Cdc42 heterozygous mutant mice were significantly higher $\left(872 \pm 105 / 0.5 \mathrm{~mm}^{2} ; p=0.027\right)$ than those in Racl homozygous mutant mice; and (5) the double homozygous mutant mice contained the highest number of outfoldings of all mice analyzed $\left(1552 \pm 156 / 0.5 \mathrm{~mm}^{2}\right)$. Our results suggest that cdc42 and rac1 cooperate, in a nonexchangeable manner, in regulating common effectors involved in the process of myelination.

\section{Discussion}

We have used a conditional tissue-specific gene ablation approach to examine the roles of the small Rho GTPases cdc 42 and rac1 in CNS myelination. This approach revealed that $\mathrm{cdc} 42$ and racl are both necessary and synergize in a gene-dosage dependent way to regulate myelination when oligodendrocyte processes ensheath axons and form compacted myelin sheaths. Ablation of Cdc42 or Rac1 leads to a unique myelin phenotype characterized by abnormal accumulation of large amounts of cytoplasm in the inner tongue and innermost lamellae of the ensheathing oligodendrocyte process, with concomitant formation of a myelin outfolding.

\section{Cdc42 is not required for OPC proliferation, directed} migration, or morphological differentiation

Our results do not support a requirement for $\mathrm{cdc} 42$ in OPC proliferation, directed migration, or in vitro morphological differentiation; however, there is a significant body of evidence showing a key role for $\mathrm{cdc} 42$ in the regulation of directed cell migration and cell morphology (Etienne-Manneville and Hall, 2002; Govek et al., 2005). In oligodendrocytes, cdc42 and racl are thought to act as positive regulators of OPC differentiation, promoting oligodendrocyte process extension and branching (Liang et al., 2004). How can we reconcile these results with our own data? Many key cellular functions ascribed to Rho GTPases rely on experiments during which their function is blocked by expression of dominant-negative mutants (Feig, 1999). Such mutants bind the corresponding activating guanine nucleotide exchange factors (GEFs) with higher affinity than do the endogenous Rho GTPases, but they do not interact with their downstream targets. Therefore, by sequestering the GEFs, they prevent the activation of endogenous Rho GTPases. A disadvantage of such an approach is the fact that GEFs activating cdc42, for example, also act on other Rho GTPases. Therefore, dominant-negative mutants of

$\leftarrow$

Figure 4. Mutant myelin sheaths are significantly thinner than control, but the specific protein composition of the myelin in mutant mice is not affected. $\boldsymbol{A}$, Graph shows the linear regressions of fiber measurements performed in the spinal cord for control (straight lines) and mutant (dashed lines) mice. Control and mutant linear regressions are significantly different ( $p=0.013)$, and the average growth ratio in mutant spinal cords is significantly higher (0.8) than in controls $(0.75)(p=0.039)$. For the growth ratio/linear regression analysis, the Welch two-sample $t$ test and the Wilcoxon rank sum test were applied. $\boldsymbol{B}$, Western blot analysis of P14 and P24 mutant and control spinal cord lysates shows no differences in the relative amounts of the myelin proteins PLP, CNP, MBP, MAG, and MOG. Actin levels confirm equal protein loading. Western blots were performed at least two times. $\boldsymbol{C}$, The periodicity of the compact myelin sheath in the mutant spinal cord is not altered. Major dense line spacing in controls and mutants is $15 \mathrm{~nm}$. D. Axon diameters of control and mutant P24 spinal cord anterolateral fiber tracts were assigned to four pre-established size categories. No significant differences were found between control and mutant axons in either category. Values are shown as mean of the measurements taken from three control and mutant mice. Error bars indicate SEs. Student's $t$ tests were used to determine significance. 
A

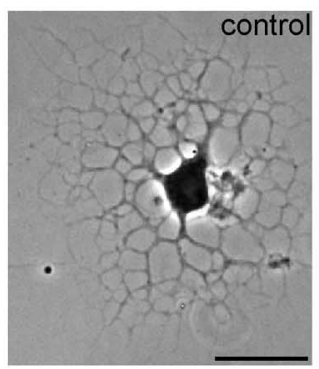

B

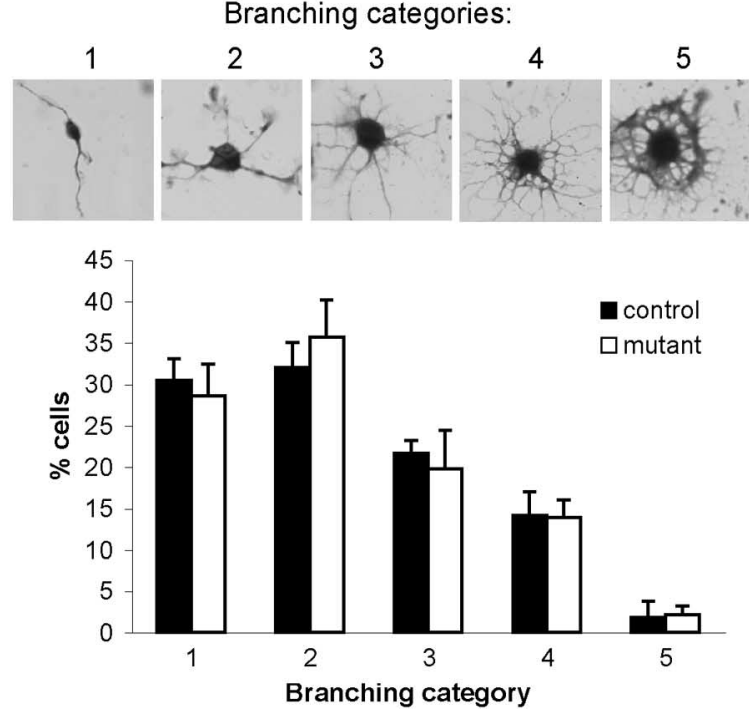

C
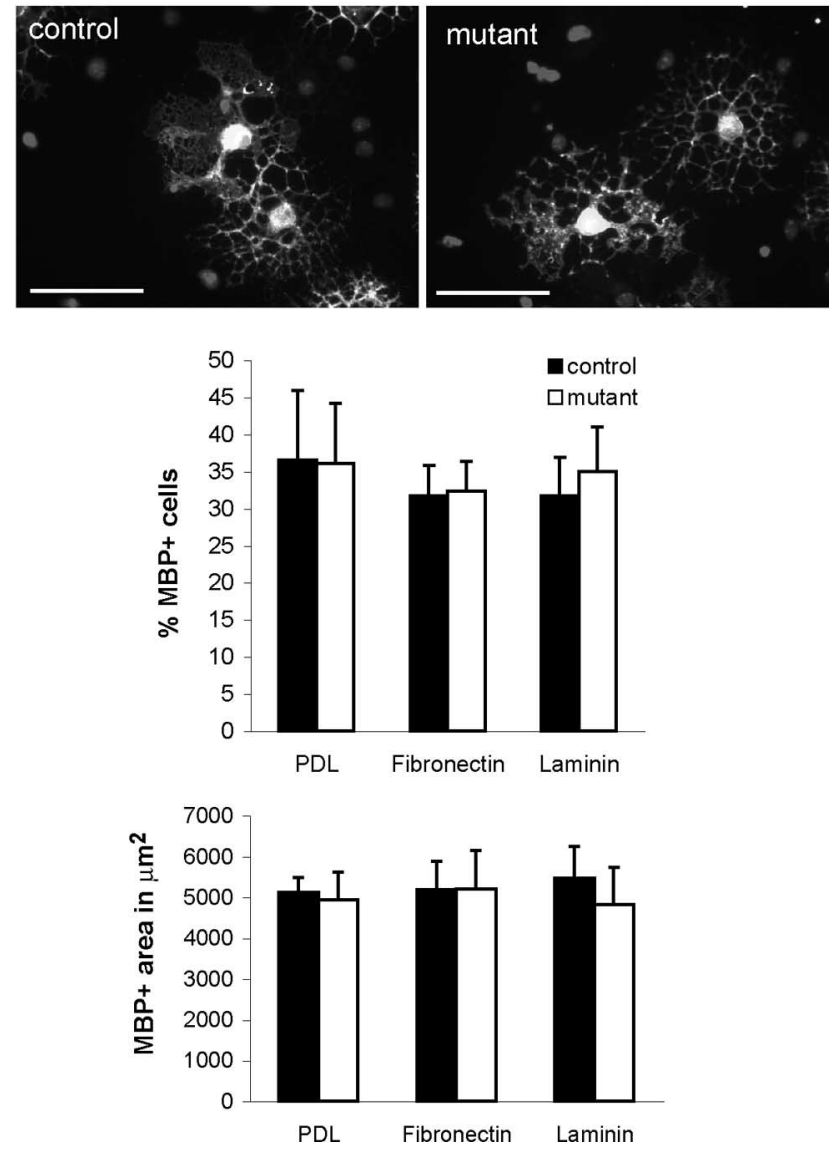

Figure 5. Mutant OPC differentiation in culture is normal. $A$, After $3 \mathrm{~d}$ of differentiation, recombined mutant and control oligodendrocytes are able to form an extensive network of primary and secondary processes. $\boldsymbol{B}$, The number of mutant and control $\mathrm{OPCs}$ assigned to different categories according to their morphological complexity is not altered significantly. $\boldsymbol{C}$, The number of MBP-positive cells present in control and mutant cultures and the extent of the myelin sheaths formed by cells acquiring MBP expression plated on PDL, fibronectin, or laminin-2 are not significantly different. Values are shown as mean of at least three independent experiments. Error bars indicate SEs. Student's $t$ test was used to determine significance. Scale bars: $\boldsymbol{A}, 25 \mu \mathrm{m} ; \boldsymbol{C}, 100 \mu \mathrm{m}$.

cdc42 may inhibit, especially if expressed at high levels (Braga et al., 2000), the activation of other Rho GTPases, making it nearly impossible to discriminate between the specific contributions from different Rho GTPases. Recent work (Czuchra et al., 2005) has shown that the transfection of $C d c 42$-null fibroblastoid cells with a $C d c 42$ dominant-negative mutant (N17 cdc42) elicits additional phenotypes that are not present in untransfected $C d c 42$ null fibroblasts. This observation raises important questions about the specificity of Rho GTPase dominant-negative approaches and is in line with previous reports showing that dominant-negative mutant expression induced more severe phenotypes than those produced by genetic loss-of-function approaches on identical cell types or organisms (Luo et al., 1994; Scott et al., 2003). Therefore, the use of conditional tissue-specific gene ablation techniques provides a stringent system for studying the roles of Rho GTPases at cellular, tissue, and organism levels.

\section{Ablation of $C d c 42$ results in the formation of aberrant myelin outfoldings}

The ablation of $C d c 42$ in oligodendrocytes led to widespread formation of aberrant myelin outfoldings, likely as a consequence of abnormal accumulation of cytoplasm in the inner tongue of the oligodendrocyte process. Such aberrant myelin outfoldings were also found occasionally in control CNS white matter. The sporadic presence of such structures during normal development has been reported previously in amphibian cerebellum (Rosenbluth, 1966). Their genesis is unclear but may be related to the deregu- lation of molecular events that accompany the early stages of axon ensheathment, in particular those associated with the removal of cytoplasm in areas in which the glial lamellae undergo compaction. During compaction, the two plasma membranes of the oligodendrocyte process come together, whereas the cytoplasm between them is excluded. The excluded cytoplasm presumably flows to regions of uncompacted myelin, which in the early developing CNS alternate irregularly with compacted myelin sheaths along the individual axon (Storts and Koestner, 1969; Remahl and Hildebrand, 1990). Our results suggest that cdc42 and $\mathrm{racl}$ signaling are involved in the regulation of this process. Given the roles played by these molecules in the regulation of cytoskeleton dynamics in different cell types, we may speculate that cytoplasm exclusion is the result of an active process and that the forces necessary to drive it are likely to be generated by the cytoskeleton. In oligodendrocytes, the organization of the microfilament and microtubule array is likely to provide the driving force for changes in plasma membrane conformation associated with process extension and branching (Simpson and Armstrong, 1999; Richter-Landsberg, 2001; Song et al., 2001). Although our results show that cdc42 is dispensable for OPC differentiation in culture, cdc42 signaling appears to be limiting in more complex and stringent cellular events for which extensive reorganization of the oligodendrocyte actin and microtubule cytoskeleton is required. This is the case during the transition from a completely unmyelinated to a fully myelinated status, a process thought to be gradual and nonuniform and most probably involving 
A

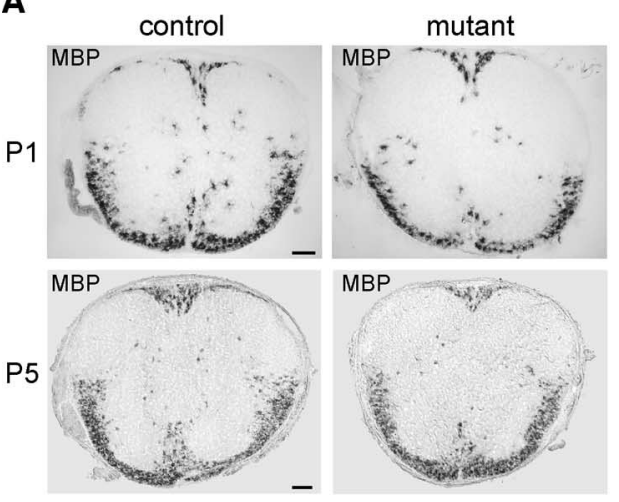

B

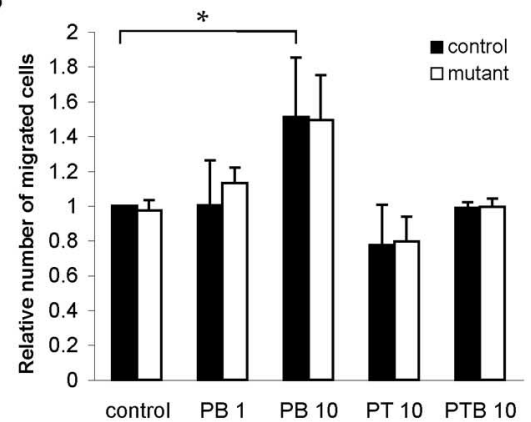

C

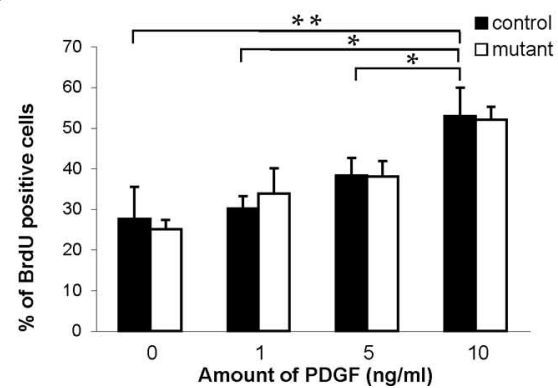

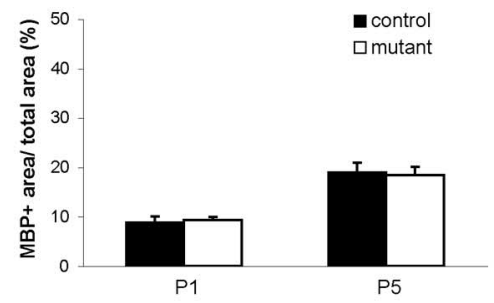

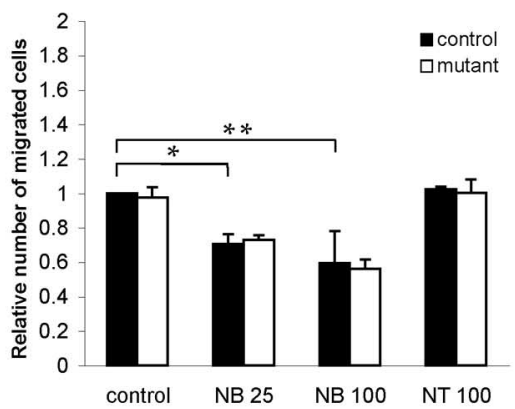

D

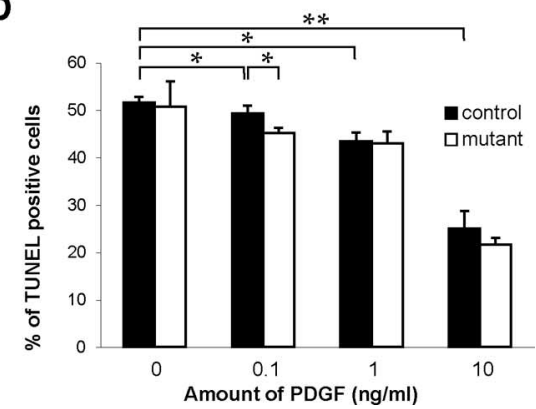

Figure 6. Loss of cdc42 does not affect the dispersion and distribution of oligodendrocytes in the spinal cord. A, At P1 and P5, MBP mRNA-positive OPCs start to accumulate in large numbers in the developing white matter. Their distribution in the ventral and dorsal fiber tracts of mutant and control mouse thoracic spinal cord is not significantly different. Values are shown as mean of three control and mutant animals per developmental stage. Error bars indicate SEs. Student's $t$ test was used to determine significance. $\boldsymbol{B}$, In Boyden chamber assays, no significant differences are found in directed migration of mutant and control OPCS in response to 1 and $10 \mathrm{ng} / \mathrm{ml}$ of the chemoattractant PDGF and to 25 and $100 \mathrm{ng} / \mathrm{ml}$ of the chemorepellent netrin-1. PB, PDGF added to bottom chamber; PT, PDGF added to top chamber; PTB, PDGF added to top and bottom chambers; NB, netrin-1 added to bottom chamber; NT, netrin-1 added to top chamber. $\boldsymbol{C}$, In response to different concentrations of the OPC mitogen PDGF, the numbers of proliferating, BrdU-positive, mutant, and control OPCs are not significantly different. $D$, Mutant OPC survival is not significantly impaired in response to PDGF. Values are shown as mean of at least three independent experiments. Error bars indicate SEs. Student's $t$ test was used to determine significance $\left({ }^{*} p<0.05 ;{ }^{* *} p<0.005\right)$. Scale bars, $100 \mu \mathrm{m}$.

Rac1 mutant

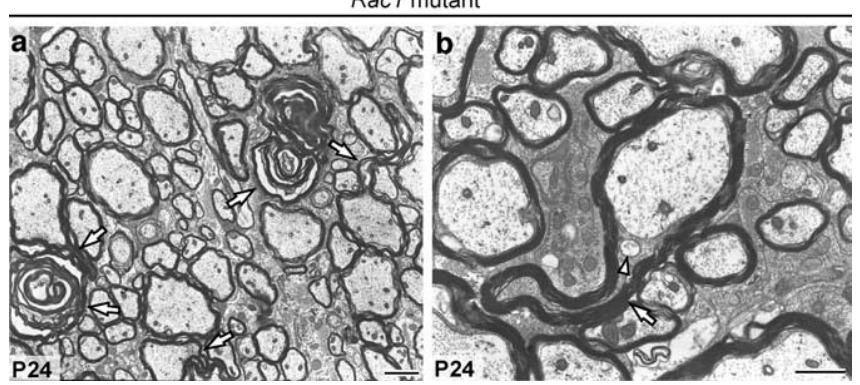

Figure 7. Rac1 is required for correct myelination. $\boldsymbol{a}, \boldsymbol{b}, \mathrm{P} 24$ Rac1 mutant spinal cords contain myelin sheath outfoldings (white arrows). Excess cytoplasm is confined to the inner tongue, which contains large vesicles (arrowhead). Scale bars: $\boldsymbol{a}, 2 \mu \mathrm{m} ; \boldsymbol{b}, 1 \mu \mathrm{m}$. elongation and extensive remodeling of the uncompacted sheaths before compaction (Remahl and Hildebrand, 1990). During this process, the lack of cdc42 may disturb normal cytoskeleton reorganization and eventually lead to the entrapment and consequent accumulation of cytoplasm in the inner tongue of the oligodendrocyte process (Fig. 3B). Perturbation of cytoskeletal reorganization and eventually of vesicle transport, also a putative function of cdc42 (Larocca and Rodriguez-Gabin, 2002; RodriguezBoulan et al., 2005), may also explain the presence of large vesicles sometimes found in the cytoplasm of the mutant cells (Figs. $2 B, 3 A$ ).

Some of the more complex myelin outfoldings present in the white matter tracts of single and double mutant mice (Fig. $8 D$ ) could have been formed as a result of axon shrinkage or even of axon degeneration; however, our results do not support these two possibilities. The diameters of axons within the anterolateral regions of the P24 mutant spinal cord were not significantly different from those in the spinal cord of control mice, and only very rarely could we find axons displaying the morphological features of axonal degeneration. In addition, it is also unlikely that retraction of myelin segments from nodal regions after myelin had been formed contributed to the formation of the myelin outfoldings, because no obvious changes in the spacing, size, and cytoarchitecture of these regions were observed.

\section{Cytoplasm accumulation in the inner tongue does not halt myelination} Despite the extraordinary enlargement of the inner tongue in mutant $C d c 42$ and Rac1 oligodendrocytes, myelination was not halted. At P24, mutant spinal cord internodes were hypomyelinated, but they were still capable of producing sizeable compacted myelin sheaths whose relative protein composition and periodicity did not differ from that of controls. In addition, the myelin sheaths in P24 axon profiles with protruding inner tongues were thicker than those at P5. This indicates that the processes regulating the addition of additional myelin wraps and their compaction were not arrested. Because it is thought that the formation of the multilamelar myelin sheath requires the continuous progression of the inner tongue over the axonal surface (Speidel, 1964; Bunge et al., 1989), it is not immediately evident to us how enlarged inner tongues, sometimes more than several axon diameters in length, are still directed to spiral around their axons. Further investigation will be required to clarify this issue.

\section{Cdc42 and rac1 synergize to regulate axon ensheathment}

Cdc42 and racl participate together in the regulation of important cellular functions in different cell types (Etienne- 


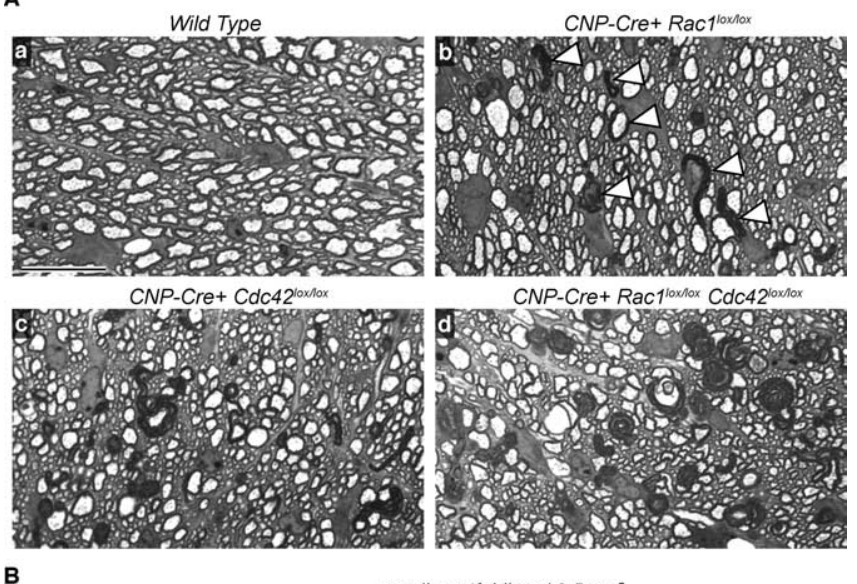

B

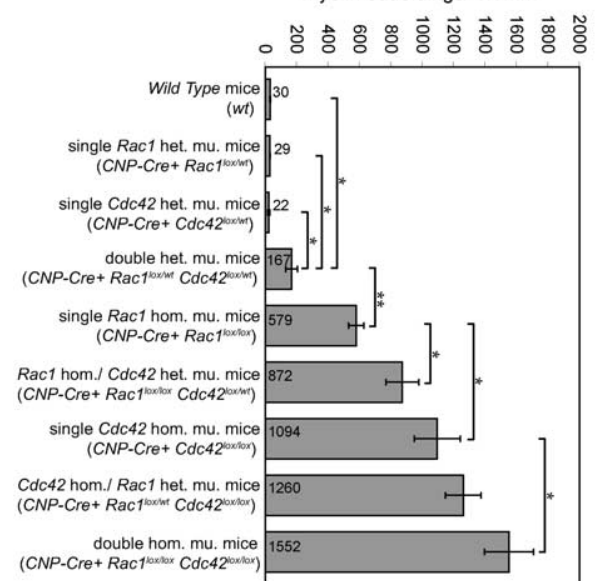

Figure 8. Cdc42 and rac1 synergize to regulate myelination. $A$, Toluidine Blue-stained semithin cross sections of wild-type $(\boldsymbol{A a})$, single Rac 1 homozygous mutant $(\boldsymbol{A} \boldsymbol{b})$, single $C d c 42$ homozygous mutant $(\boldsymbol{A c})$, and double homozygous mutant (Ad) spinal cords. Myelin sheath outfoldings $(\boldsymbol{A} \boldsymbol{b}$, arrowheads) are easily recognizable $(\boldsymbol{A} \boldsymbol{b}-\boldsymbol{A d})$. Note their gradual increase in frequency and size from Rac1 mutants $(\boldsymbol{A} \boldsymbol{b})$ over $(d \boldsymbol{c} 42$ mutants $(\boldsymbol{A c})$ to double homozygous mutants $(\boldsymbol{A d})$. Scale bars, $20 \mu \mathrm{m}$. $\boldsymbol{B}$, Cdc42 and rac1 cooperate to regulate myelination in a gene-dosage dependent manner. Graph shows the number of myelin outfoldings per area unit counted on cross sections of different $C d c 42$ and Rac 1 mutant spinal cords. Values are given as means of three animals per genotype. Error bars indicate SES. Statistical significance was determined with the Student's $t$ test $\left({ }^{*} p<0.05 ;{ }^{* *} p<0.005\right)$. het. mu., Heterozygous mutant; hom. mu., homozygous mutant.

Manneville and Hall, 2002; Govek et al., 2005). Therefore, we analyzed the genetic interactions between $C d c 42$ and Racl in the regulation of CNS myelination. Combining conditional alleles for both genes revealed that the effects of the ablation of $C d c 42$ and Racl were cooperative in severity. Double heterozygous mutants contained more outfoldings than wildtype, single $C d c 42$, or Racl heterozygous mutants; Rac1 homozygous/Cdc42 heterozygous mutants contained more outfoldings than single Rac1 homozygous mutants, and the double homozygous mutants had the highest number of myelin outfoldings of all genotypes analyzed. Because the number of outfoldings in the single $C d c 42$ homozygous mutant was already much higher than in the single Rac1 homozygous mutant mice, only a modest and nonsignificant increase in the number of outfoldings was observed in the $C d c 42$ homozygous/Rac1 heterozygous mutants as compared with single homozygous $C d c 42$ mutant mice. Our results also suggest that cdc42 does not directly regulate racl activity. If racl activity were regulated by $c d c 42$, no increase in the number of myelin outfoldings would have been observed in the double homozygote compared with the single $C d c 42$ homozygous mutant mice. Indeed, pull-down assays performed in mutant $C d c 42$ OPCs confirmed that the levels of both racl activity and expression were not significantly regulated (supplemental Fig. 1, available at www.jneurosci.org as supplemental material).

Overall, our results show a stage-specific and critical requirement for cdc42 and racl in the regulation of myelination. The phenotype produced by their genetic ablation in oligodendrocytes is unique, and an important task for the future will be to determine how these molecules are regulated and which pathways they control in the context of CNS myelination.

\section{References}

Baron W, Colognato H, Ffrench-Constant C (2005) Integrin-growth factor interactions as regulators of oligodendroglial development and function. Glia 49:467-479.

Barres BA, Hart IK, Coles HS, Burne JF, Voyvodic JT, Richardson WD, Raff MC (1992) Cell death and control of cell survival in the oligodendrocyte lineage. Cell 70:31-46.

Benninger Y, Colognato H, Thurnherr T, Franklin RJ, Leone DP, Atanasoski S, Nave KA, Ffrench-Constant C, Suter U, Relvas JB (2006) Beta1integrin signaling mediates premyelinating oligodendrocyte survival but is not required for CNS myelination and remyelination. J Neurosci 26:7665-7673.

Besnard F, Perraud F, Sensenbrenner M, Labourdette G (1987) Plateletderived growth factor is a mitogen for glial but not for neuronal rat brain cells in vitro. Neurosci Lett 73:287-292.

Braga VM, Betson M, Li X, Lamarche-Vane N (2000) Activation of the small GTPase Rac is sufficient to disrupt cadherin-dependent cell-cell adhesion in normal human keratinocytes. Mol Biol Cell 11:3703-3721.

Bunge RP, Bunge MB, Bates M (1989) Movements of the Schwann cell nucleus implicate progression of the inner (axon-related) Schwann cell process during myelination. J Cell Biol 109:273-284.

Buttery PC, ffrench-Constant C (1999) Laminin-2/integrin interactions enhance myelin membrane formation by oligodendrocytes. Mol Cell Neurosci 14:199-212.

Chrostek A, Wu X, Quondamatteo F, Hu R, Sanecka A, Niemann C, Langbein L, Haase I, Brakebusch C (2006) Racl is crucial for hair follicle integrity but is not essential for maintenance of the epidermis. Mol Cell Biol 26: 6957-6970.

Cotteret S, Chernoff J (2002) The evolutionary history of effectors downstream of Cdc42 and Rac. Genome Biol 3:REVIEWS0002.

Czuchra A, Wu X, Meyer H, van Hengel J, Schroeder T, Geffers R, Rottner K, Brakebusch C (2005) Cdc42 is not essential for filopodium formation, directed migration, cell polarization, and mitosis in fibroblastoid cells. Mol Biol Cell 16:4473-4484.

Erschbamer MK, Hofstetter CP, Olson L (2005) RhoA, RhoB, RhoC, Racl, Cdc42, and Tc10 mRNA levels in spinal cord, sensory ganglia, and corticospinal tract neurons and long-lasting specific changes following spinal cord injury. J Comp Neurol 484:224-233.

Etienne-Manneville S (2004) Cdc42-the centre of polarity. J Cell Sci 117:1291-1300.

Etienne-Manneville S, Hall A (2002) Rho GTPases in cell biology. Nature 420:629-635.

Feig LA (1999) Tools of the trade: use of dominant-inhibitory mutants of Ras-family GTPases. Nat Cell Biol 1:E25-27.

Genoud S, Lappe-Siefke C, Goebbels S, Radtke F, Aguet M, Scherer SS, Suter U, Nave KA, Mantei N (2002) Notch1 control of oligodendrocyte differentiation in the spinal cord. J Cell Biol 158:709-718.

Govek EE, Newey SE, Van Aelst L (2005) The role of the Rho GTPases in neuronal development. Genes Dev 19:1-49.

Hall A (1998) Rho GTPases and the actin cytoskeleton. Science 279:509-514.

Jaffe AB, Hall A (2005) Rho GTPases: biochemistry and biology. Annu Rev Cell Dev Biol 21:247-269.

Jarjour AA, Manitt C, Moore SW, Thompson KM, Yuh SJ, Kennedy TE (2003) Netrin-1 is a chemorepellent for oligodendrocyte precursor cells in the embryonic spinal cord. J Neurosci 23:3735-3744.

Lappe-Siefke C, Goebbels S, Gravel M, Nicksch E, Lee J, Braun PE, Griffiths 
IR, Nave KA (2003) Disruption of Cnp1 uncouples oligodendroglial functions in axonal support and myelination. Nat Genet 33:366-374.

Larocca JN, Rodriguez-Gabin AG (2002) Myelin biogenesis: vesicle transport in oligodendrocytes. Neurochem Res 27:1313-1329.

Liang X, Draghi NA, Resh MD (2004) Signaling from integrins to Fyn to Rho family GTPases regulates morphologic differentiation of oligodendrocytes. J Neurosci 24:7140-7149.

Luo L, Liao YJ, Jan LY, Jan YN (1994) Distinct morphogenetic functions of similar small GTPases: Drosophila Drac1 is involved in axonal outgrowth and myoblast fusion. Genes Dev 8:1787-1802.

McCarthy KD, de Vellis J (1980) Preparation of separate astroglial and oligodendroglial cell cultures from rat cerebral tissue. J Cell Biol 85:890-902.

McKinnon RD, Smith C, Behar T, Smith T, Dubois-Dalcq M (1993) Distinct effects of bFGF and PDGF on oligodendrocyte progenitor cells. Glia 7:245-254.

Mi S, Miller RH, Lee X, Scott ML, Shulag-Morskaya S, Shao Z, Chang J, Thill G, Levesque M, Zhang M, Hession C, Sah D, Trapp B, He Z, Jung V, McCoy JM, Pepinsky RB (2005) LINGO-1 negatively regulates myelination by oligodendrocytes. Nat Neurosci 8:745-751.

Miller RH (2002) Regulation of oligodendrocyte development in the vertebrate CNS. Prog Neurobiol 67:451-467.

Relvas JB, Setzu A, Baron W, Buttery PC, LaFlamme SE, Franklin RJ, FfrenchConstant C (2001) Expression of dominant-negative and chimeric subunits reveals an essential role for betal integrin during myelination. Curr Biol 11:1039-1043.

Remahl S, Hildebrand C (1990) Relations between axons and oligodendroglial cells during initial myelination. II. The individual axon. J Neurocytol 19:883-898.

Richter-Landsberg C (2001) Organization and functional roles of the cytoskeleton in oligodendrocytes. Microsc Res Tech 52:628-636.

Ridley AJ, Schwartz MA, Burridge K, Firtel RA, Ginsberg MH, Borisy G,
Parsons JT, Horwitz AR (2003) Cell migration: integrating signals from front to back. Science 302:1704-1709.

Rodriguez-Boulan E, Kreitzer G, Musch A (2005) Organization of vesicular trafficking in epithelia. Nat Rev Mol Cell Biol 6:233-247.

Rosenbluth J (1966) Redundant myelin sheaths and other ultrastructural features of the toad cerebellum. J Cell Biol 28:73-93.

Saher G, Brugger B, Lappe-Siefke C, Mobius W, Tozawa R, Wehr MC, Wieland F, Ishibashi S, Nave KA (2005) High cholesterol level is essential for myelin membrane growth. Nat Neurosci 8:468-475.

Sander EE, van Delft S, ten Klooster JP, Reid T, van der Kammen RA, Michiels F, Collard JG (1998) Matrix-dependent Tiam1/Rac signaling in epithelial cells promotes either cell-cell adhesion or cell migration and is regulated by phosphatidylinositol 3-kinase. J Cell Biol 143:1385-1398.

Scott EK, Reuter JE, Luo L (2003) Small GTPase Cdc42 is required for multiple aspects of dendritic morphogenesis. J Neurosci 23:3118-3123.

Simpson PB, Armstrong RC (1999) Intracellular signals and cytoskeletal elements involved in oligodendrocyte progenitor migration. Glia 26:22-35.

Song J, Goetz BD, Baas PW, Duncan ID (2001) Cytoskeletal reorganization during the formation of oligodendrocyte processes and branches. Mol Cell Neurosci 17:624-636.

Soriano P (1999) Generalized lacZ expression with the ROSA26 Cre reporter strain. Nat Genet 21:70-71.

Speidel CC (1964) In vivo studies of myelinated nerve fibers. Int Rev Cytol $16: 173-231$.

Storts RW, Koestner A (1969) Development and characterization of myelin in tissue culture of canine cerebellum. Z Zellforsch Mikrosk Anat 95:9-18.

Wu X, Quondamatteo F, Lefever T, Czuchra A, Meyer H, Chrostek A, Paus R, Langbein L, Brakebusch C (2006) Cdc42 controls progenitor cell differentiation and beta-catenin turnover in skin. Genes Dev 20:571-585. 